\title{
Motoneurons Have Different Membrane Resistance during Fictive Scratching and Weight Support
}

\author{
Marie-Claude Perreault ${ }^{1,2}$ \\ ${ }^{1}$ Department of Physiology, Panum Institute, 2200 Copenhagen, Denmark, and 2Department of Physiology, \\ University of Oslo, 0317 Oslo, Norway
}

The passive membrane properties of motoneurons may be affected in a behavior-specific manner because of differences in synaptic drive during different motor behaviors. To explore this possibility, the changes in input resistance $\left(R_{\text {in }}\right)$ and membrane time constant $\left(\tau_{\mathrm{m}}\right)$ of single extensor motoneurons were compared during two different types of motor activities: fictive scratching and fictive weight support. These two activities were selected because the membrane potential of extensor motoneurons follows a very different trajectory during fictive scratching (multiphasic, mostly rhythmic trajectory) and fictive weight support (monophasic, tonic trajectory). The intracellular recordings were performed in vivo in the immobilized, decerebrate cat using QX314-containing microelectrodes to block action potentials.

The $R_{\text {in }}$ and $\tau_{m}$ at rest (control) were reduced substantially during all phases of fictive scratching. In contrast, $\mathrm{R}_{\text {in }}$ and $\tau_{\mathrm{m}}$ changed only little during fictive weight support. Such a differ- ential effect on the membrane resistance was observed even in motoneurons in which the peak voltage of the rhythmic depolarization during scratching was similar to the peak voltage of the tonic depolarization during weight support. The differential effect was attributed mainly to a difference in synaptic drive and, in particular, to a larger amount of inhibitory synaptic activity during fictive scratching.

The present study demonstrates how the same motoneuron can have a different membrane resistance while participating in two different behaviors. Such tuning of the membrane resistance may provide motoneurons with behavior-specific integrative capabilities that, in turn, could be used advantageously to increase motor performance.

Key words: locomotion; central pattern generator; spinal cord; synaptic integration; membrane conductance; glycine; postsynaptic inhibition; chloride
Synaptic signaling in an active neuronal network influences the membrane resistance of the neurons and, by that, their integrative properties. As the function of the network changes, the membrane properties of the neurons could be modified and, thus, become task specific.

Motoneurons are one type of multitask neuron for which we have a good understanding of their membrane properties and synaptic mechanisms that control them (for review, see Rekling et al., 2000). Even with this type of neuron, however, very little is known of the behavioral circumstances that may alter its membrane properties. Locomotion is one activity that can significantly reduce the resistance of motoneurons (rats: Cazalets et al., 1996; cats: Shefchyk and Jordan 1985; Gosgnach et al., 2000). The magnitude of the reduction in motoneuronal resistance during fictive locomotor activity is comparable in different preparations (average reductions between 20 and 40\%) and is even similar to that of other spinal neurons (average reduction of 35\%) (Raastad et al., 1998). This could mean that there is an optimal change in membrane resistance during locomotion or rhythmic activities in

Received Feb. 11, 2002; revised May 22, 2002; accepted June 21, 2002.

The present experiments were performed in Denmark in the laboratory of Prof. Hans Hultborn and were supported by grants from the Danish Medical Research Council, the Lundbeck Foundation, and the Novo Nordisk Foundation. Many thanks to Lillian Grøndahl for her assistance during this investigation. I am also grateful to Drs. M. Tresch and M. Raastad and Prof. H. Hultborn for their helpful comments on this manuscript.

Correspondence should be addressed to Marie-Claude Perreault, Department of Physiology, University of Oslo (Domus Medica), Sognsvannsveien 9, 0317 Oslo, Norway. E-mail: m.c.perreault@basalmed.uio.no.

Copyright (C) 2002 Society for Neuroscience $0270-6474 / 02 / 228259-07 \$ 15.00 / 0$ general. Such a hypothesis is appealing and could be addressed by increasing the repertoire of motor activities investigated.

One way to estimate the influence of specific levels of synaptic activity on motoneurons would be to compare the changes in resistance during different types of motor activities. However, such an approach puts severe constraints on experimental preparations, which needs to exhibit more than one behavior. The paralyzed, decerebrate cat preparation allows recording from single motoneurons and has a relatively quiet spinal network that can be readily activated into different types of behaviors (Degtyarenko et al., 1998; Perreault et al., 1999). The preparation is thus particularly well suited for testing the possibility that different types of network activity produce different changes in the input resistance $\left(\mathrm{R}_{\mathrm{in}}\right)$ of motoneurons.

In the present study, the immobilized, decerebrate cat was used to examine the changes in $\mathrm{R}_{\mathrm{in}}$ and membrane time constant $\left(\tau_{\mathrm{m}}\right)$ of extensor motoneurons during fictive scratching (rhythmic pattern) and fictive weight support (tonic pattern). Successful intracellular recordings from motoneurons during these activities have been obtained routinely in this preparation (scratching: Berkinblit et al., 1980; Degtyarenko et al., 1998; Perreault et al., 1999; weight support: Perreault et al., 1999) but have never been used to compare changes in $\mathrm{R}_{\mathrm{in}}$ between motor activities. Different methods were used to estimate the changes in $\mathrm{R}_{\mathrm{in}}$. All methods lead to the conclusion that fictive scratching and fictive weight support differently alter the membrane resistance of motoneurons. The data also suggest that this differential effect is mainly attributable to a difference in synaptic drive.

Parts of this work have been published previously in abstract form (Perreault, 1999). 


\section{MATERIALS AND METHODS}

Preparation. Data were obtained from experiments performed on five adult cats $(1.9-3.5 \mathrm{~kg})$. A detailed description of the preparation can be found by Perreault et al. (1999). Briefly, after anesthesia with halothanenitrous oxide $\left(2-3 \%\right.$ halothane, $70 \% \mathrm{~N}_{2} \mathrm{O}$, and $\left.30 \% \mathrm{O}_{2}\right)$, the animals were intubated, and cannulas were inserted in the jugular veins for administration of fluid and drugs and in the carotid artery for blood pressure monitoring. Atropine ( $0.1 \mathrm{mg} / \mathrm{kg}$, s.c.) and dexamethasone ( $1 \mathrm{mg} / \mathrm{kg}$, i.v.) were given at the beginning of the experiment while buffer solution $(10 \%$ dextrose and $\left.1.7 \% \mathrm{NaHCO}_{3}\right)$ was infused continuously $(4.5 \mathrm{ml} / \mathrm{hr})$.

In all experiments, the following nerves from the left hindlimb were cut, dissected, and mounted for recording or stimulation: sartorius (both medial and lateral branches), semimembranosus and anterior biceps (SmAB), posterior biceps and semitendinosus (PBSt), medial gastrocnemius (MG), lateral gastrocnemius and soleus (LGS), plantaris (PL) and tibialis anterior (TA). In two experiments, quadriceps (with the rectus femoris portion included), flexor digitorum, and hallucis longus, as well as branches to interosseous, tibialis posterior and popliteal muscles, and extensor digitorum longus were also dissected. From the right limb, the gastrocnemius nerves and TA or PBSt were mounted. In all cats, the remaining femoral, sciatic, and obturator nerve branches and the tendons around the hips were cut bilaterally. After a first laminectomy exposing L4-S1 spinal cord segments, the animal was transferred to a rigid frame. There, a second laminectomy exposing $\mathrm{C} 1-\mathrm{C} 2$ segments and a precollicular-postmammillary decerebration (with all brain tissue rostral to the transection removed) were performed. Anesthesia was then discontinued, and the animal was paralyzed with pancuron bromide (Pavulon; $\left.4 \mathrm{mg} \cdot \mathrm{kg}^{-1} \cdot \mathrm{hr}^{-1}\right)$. The expired $\mathrm{CO}_{2}$ was maintained between 3.0 and $5.0 \%$ by artificial ventilation. Animal temperature was kept near $38^{\circ} \mathrm{C}$ by infrared lamps. The procedures were approved by the National Ethics Committee in Denmark.

Induction of fictive scratching and fictive weight support. Bouts of fictive scratching and weight support were elicited by manual stimulation of the left and right outer ear (pinna), respectively, after transient application of a small piece of cotton soaked in $d$-tubocurarine $(0.1$ or $0.3 \%)$ at $\mathrm{C} 1$ and C2 dorsal root entry zones (Domer and Feldberg, 1960; Feldberg and Fleischhauer, 1960). $d$-Tubocurarine is presumed to facilitate scratching activity through disinhibition of propriospinal neurons (cf. Gelfand et al., 1988). The functional relationship between the population responses recorded in the present preparation [electroneurograms (ENGs)] and in the intact animal (electromyograms) is discussed by Perreault et al. (1999).

Data recording. Motoneurons were recorded intracellularly with sharp microelectrodes (tip diameter, 1.0-1.4 $\mu \mathrm{m}$; resistance, 2.5-4 M $\Omega$ ) filled with the lidocaine derivative QX-314 (50 mM) in $2 \mathrm{M}$ potassium acetate. QX-314 was used to block the action potential and to help isolate the synaptic part of the conductance around the voltage range for spike generation. Motoneurons were identified antidromically by stimulating the left hindlimb nerves before the action potential was affected by QX-314. The recordings were made in discontinuous current-clamp mode (sampling frequency, 2-4 kHz; output filtering, $1 \mathrm{kHz}$; Axoclamp amplifier; Axon Instruments, Foster City, CA). To assess the excitability of the various motoneuron pools and monitor the motor state of the animal, integrated and rectified ENGs from left and the right hindlimb nerves were used.

ENGs, current monitor output, and AC-coupled (cord dorsum potentials and intracellular records) and DC-coupled (intracellular records) recordings were digitized at a rate of $500 \mathrm{~Hz}, 5,10$, and $5 \mathrm{kHz}$, respectively. Data were collected for off-line analysis with software developed within the Winnipeg Spinal Cord Research Centre (University of Manitoba, Winnipeg, Canada) to run under real-time Linux (http://www. scrc.umanitoba.ca/doc).

Analysis. The magnitudes of the changes in membrane potential, $\mathrm{R}_{\mathrm{in}}$, and $\tau_{\mathrm{m}}$ during fictive scratching and weight support were measured. Fictive scratching (see Fig. $1 A$ ) was divided into two main periods: a tonic period characterized by a tonic hyperpolarization (TH) and a rhythmic period characterized by alternating, rhythmic depolarizations (RDs) and rhythmic hyperpolarizations (RHs). The amplitude of TH was measured with respect to the membrane potential at rest, whereas the amplitudes of $\mathrm{RD}$ and $\mathrm{RH}$ were measured with respect to the membrane potential during the TH. In contrast, fictive weight support consisted mainly of a tonic period in which the motoneurons were depolarized. Riding on the top of the tonic depolarization, small rhythmic hyperpolarizations were sometimes seen (see Fig. $1 B$ ). These potentials, when present, marked the onset of contralateral scratching activity (data not shown) (but see Perreault et al., 1999). The amplitude of the tonic depolarization during weight support was measured with respect to the membrane potential at rest.

The changes in membrane resistance were estimated from the changes in $\mathrm{R}_{\mathrm{in}}$ and $\tau_{\mathrm{m}}$, which, in turn, were evaluated from the changes in voltage responses to short hyperpolarizing and, sometimes depolarizing, current pulses $(1.5-4 \mathrm{nA}, 5-15 \mathrm{msec})$. Depolarizing pulses that clearly induced smaller voltage deflection than hyperpolarizing pulses were assumed to have activated voltage-sensitive conductances and, therefore, were not used for $\mathrm{R}_{\mathrm{in}}$ or $\tau_{\mathrm{m}}$ measurements. Current pulses were delivered throughout the recording sessions (free-running delivery at $3-7 \mathrm{~Hz}$ ), and, in some experiments, they were superimposed on constant-current injections (see Fig. 4). Because of the short duration of the RD phase of scratching ( $~ 35$ $\mathrm{msec})$, it was not possible to use current pulses of long enough duration for the voltage responses to reach steady-state levels. As a consequence, the peak of the voltage response could not be used to determine the absolute $\mathrm{R}_{\text {in }}$. Instead, the absolute $\mathrm{R}_{\text {in }}$ was calculated by two other methods. The first method (integral method; see Fig. 2D) consisted of dividing the integral of the voltage response by the integral of the current pulse (Barrett and Barrett, 1976). The other consisted of fitting the rising phase of the voltage response by a two- or sometimes three-exponential terms equation: $V(t)=k_{0}\left(1-\exp \left(-t / \tau_{0}\right)+k_{1}\left(1-\exp \left(-t / \tau_{1}\right)+k_{\mathrm{sag}}(1-\right.\right.$ $\exp \left(-t / \tau_{\text {sag }}\right)$. The third exponential term was used only when an obvious overshoot of the voltage response (sag) was present (Ito and Oshima, 1965). After the fitting, $\mathrm{R}_{\mathrm{in}}$ was obtained by dividing the sum of the coefficients $k_{0}$ and $k_{1}$ by the amplitude of the current pulse [ $\Sigma$ of exponential (exp) coefficients; see Fig. 2D]. The fitting procedure was also used to determine $\tau_{\mathrm{m}}$, which was assumed to be equivalent to $\tau_{\mathrm{o}}$ (a valid assumption if the specific electrical properties of the motoneurons are uniform). With the above two methods, absolute $\mathrm{R}_{\text {in }}$ values of $1.32 \pm$ 0.12 (with the integral method) and $1.54 \pm 0.13 \mathrm{M} \Omega$ (with the fitting method) were obtained. These values are similar to the $R_{\text {in }}$ values reported routinely in the literature for this type of cell (cf. Burke and ten Bruggencate, 1971; Gustafsson and Pinter, 1984; Zengel et al., 1985; Hochman and McCrea, 1994). At least in theory, it is possible that these values diverge from the true, yet unknown, $R_{\text {in }}$ value because of technical factors. For instance, QX-314 in the electrode solution could give a value larger than the true $\mathrm{R}_{\mathrm{in}}$ value, whereas a leak around the electrode could give an underestimate. As it will be argued in Discussion, however, such technical factors are unlikely to impact on the conclusions of this study.

During fictive scratching, the voltage responses occurring during the tonic and rhythmic phases were averaged separately, and all individual voltage responses that showed obvious contamination by a large shift in baseline (such as those seen during phase transitions) were excluded from the average. During weight support, only the voltage responses recorded after the membrane potential had reached a tonic plateau and that were not contaminated by small rhythmic hyperpolarizing potentials were averaged. Unless stated otherwise, statistics are given as mean $\pm \mathrm{SE}$. Differences between the means were tested with one-way ANOVA using either the Dunett's (for comparison against a control group) or Tukey's (for pair-wise comparisons) method $(\alpha=0.05)$.

\section{RESULTS}

Only motoneurons identified as extensor motoneurons were included in this study. The mean resting membrane potential was $-56.5 \pm 2.6 \mathrm{mV}(n=13)$. There was no significant difference between the mean resting $\mathrm{R}_{\text {in }}$ obtained with the integral method and that obtained with the fitting method (see Materials and Methods). The mean $\tau_{\mathrm{m}}$ was $5.43 \pm 0.11 \mathrm{msec}$, consistent with the values reported from studies in anesthetized, intact cats (Burke and ten Bruggencate, 1971; Gustafsson and Pinter, 1984; Zengel et al., 1985; Hochman and McCrea, 1994).

\section{Driving potentials during fictive scratching and weight support}

Most of the motoneurons were recorded during both fictive scratching ( $n=11$ of 13$)$ and fictive weight support ( $n=12$ of 13$)$. During fictive scratching, the membrane potential was initially driven by a TH and then by alternating RDs and RHs (Fig. $1 A$, top trace). The initial $\mathrm{TH}$ and the succeeding RDs and RHs had a mean amplitude of $-5.3 \pm 1.9,13.1 \pm 1.4$, and $-2.3 \pm 0.4 \mathrm{mV}$, 
A Fictive Scratching

Rhythmic period

(alternating de- and hyperpolarizations)
B

Fictive Weight Support

Tonic period

(tonic depolarization)

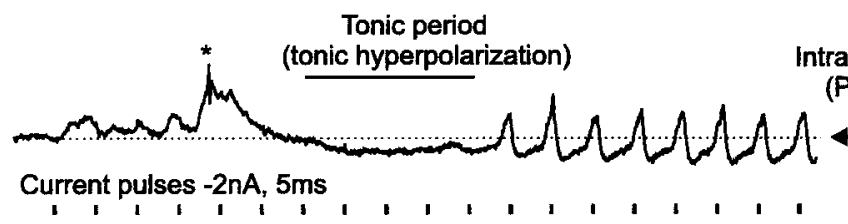

Intracellular recording (PI motoneuron)

$-58 \mathrm{mV} \rightarrow$

Rectified, integrated ENGS

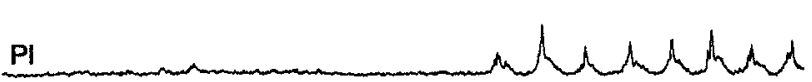

(left hindlimb)

PI

PI

TA

TA

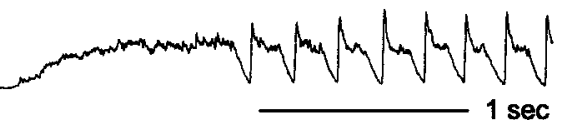

Figure 1. Membrane potential trajectory during fictive scratching and weight support. $A, B$, Intracellular recordings from a Pl1 motoneuron (top trace) during fictive scratching and fictive weight support, respectively. During fictive scratching, the membrane was first tonically hyperpolarized (tonic period). This initial tonic hyperpolarization was followed by membrane oscillations (rhythmic period). Contrasting with this pattern, the membrane during fictive weight support was tonically depolarized. Asterisks indicate spike attenuated by QX-314. The resting membrane potential of this motoneurons was -58 $\mathrm{mV}$ (horizontal dotted lines). The $15 \mathrm{mV}$ voltage scale in $B$ is also valid in $A$. Current pulses were delivered continuously during the recording sessions (vertical bars) to monitor the input resistance before, during, and after fictive motor activities. The rectified and integrated ENGs were used to monitor the excitability of the different motoneuron pools and assess changes in motor state. For the sake of clarity, only two ENGs are shown here (bottom traces): one from the ankle extensor nerve $\mathrm{Pl}$ and the other from the ankle flexor nerve TA.

respectively (see Materials and Methods). During fictive weight support, the membrane potential was mostly driven by a tonic depolarization (Fig. 1B, top trace). This tonic depolarization had a mean amplitude of $11.0 \pm 2.1 \mathrm{mV}$.

In a subpopulation of motoneurons ( $n=4$; P13, P14, LGS5, and SmAB1), the membrane voltage during the RD phase of scratching $(12.2 \pm 2.2 \mathrm{mV})$ was similar to the membrane voltage during the tonic depolarization of weight support $(10.8 \pm 1.4 \mathrm{mV})$. This gave a unique opportunity to compare the $\mathrm{R}_{\text {in }}$ at comparable membrane potentials but during different behaviors.

\section{Changes in input resistance during fictive scratching and fictive weight support}

Changes in $\mathrm{R}_{\text {in }}$ were estimated using three different measurements: the peak of the voltage response, the integral of the voltage response, and the fit of its rising phase (see Materials and Methods). Unless indicated otherwise, the values reported are those obtained with the integral method.

During fictive scratching, substantial reductions in $\mathrm{R}_{\mathrm{in}}(>25 \%)$ were seen in both ankle and hip extensor motoneurons. There were no systematic differences whether $R_{\text {in }}$ was tested with negative or positive current pulses. On average, the $\mathrm{R}_{\text {in }}$ during fictive scratching (averages across all phases) was reduced by $36.7 \pm$ $4.1 \%$. In contrast, the average $\mathrm{R}_{\text {in }}$ during fictive weight support was changed by $<1 \%$ (decreased by $0.9 \pm 4.3 \%$ ). The differential effect of fictive scratching and weight support on the $\mathrm{R}_{\text {in }}$ was manifest even within the subpopulation of motoneurons that had similar membrane voltage during the RD phase of scratching and during the tonic depolarization of weight support $(n=4$; see Results, Driving potentials during fictive scratching and weight support). In this subpopulation, the $\mathrm{R}_{\text {in }}$ was reduced by $23.0 \pm$ $2.9 \%$ during the RD phase of scratching, whereas it was increased by $13.0 \pm 3.2 \%$ during weight support.

An example of the differential effect of fictive scratching and weight support on the $\mathrm{R}_{\mathrm{in}}$ of extensor motoneurons is shown in Figure 2. In this example, the changes in $\mathrm{R}_{\text {in }}$ were monitored using hyperpolarizing current pulses ( $-4 \mathrm{nA}, 5 \mathrm{msec})$. As can be judged from the difference between the average voltage response at rest (control) and the average voltage responses during scratching ( $\mathrm{TH}, \mathrm{RD}$, and $\mathrm{RH}$ phases), there was a clear reduction in $\mathrm{R}_{\mathrm{in}}$ during all phases of fictive scratching (Fig. $2 A$ ). In contrast, there was virtually no difference between the average voltage responses at rest and during fictive weight support (Fig. $2 B$ ). The $\mathrm{R}_{\text {in }}$ during fictive scratching (all phases averaged) was decreased by $60.5 \%$ $(39.5 \pm 2.5 \%$ of control) compared with $8.0 \%(92.0 \pm 3.2 \%$ of control) during fictive weight support (Fig. $2 C$ ). As evidenced by the faster rising phase of the voltage responses, $\tau_{\mathrm{m}}$ was also more reduced during scratching than weight support. The correlation between the changes in $\mathrm{R}_{\mathrm{in}}$ and $\tau_{\mathrm{m}}$ was strong during both motor activities ( $r=0.91$ during scratching and $r=0.97$ during weight support). Figure $2 D$ shows that all types of measurements used in this study could effectively disclose the differential effect of scratching and weight support on the membrane resistance of extensor motoneurons.

\section{Phasic modulation of $\mathbf{R}_{\text {in }}$ during fictive scratching}

Fluctuations of $\mathrm{R}_{\text {in }}$ during the different phases of scratching such as shown in Figure $2 C$ were commonly observed (Fig. $3 A$ ). In all cases, the $\mathrm{R}_{\text {in }}$ was maximally reduced when the motoneurons were relatively hyperpolarized, i.e., either during TH or RH. The average decrease was $36.9 \pm 4.0 \%$ during $\mathrm{TH}$ compared with $30.0 \pm 4.7 \%$ during RD and $43.1 \pm 4.1 \%$ during RH (Fig. $3 B$ ). Whereas the mean $\mathrm{R}_{\text {in }}$ during each phase was different from the mean control $\mathrm{R}_{\text {in }}(p=0.0003)$, when it was compared with the mean $\mathrm{R}_{\mathrm{in}}$ of other phases, a significant difference could not be established. This suggests that there is only a weak phasic modulation of $\mathrm{R}_{\mathrm{in}}$ during the different phases of fictive scratching.

\section{Continuous intracellular current injections}

The purpose of continuous current injections was twofold: first, to examine the possibility of a contribution from voltage-sensitive conductances to the observed decrease in $\mathrm{R}_{\text {in }}$ and, second, to investigate the synaptic nature of the inhibitory driving potentials 

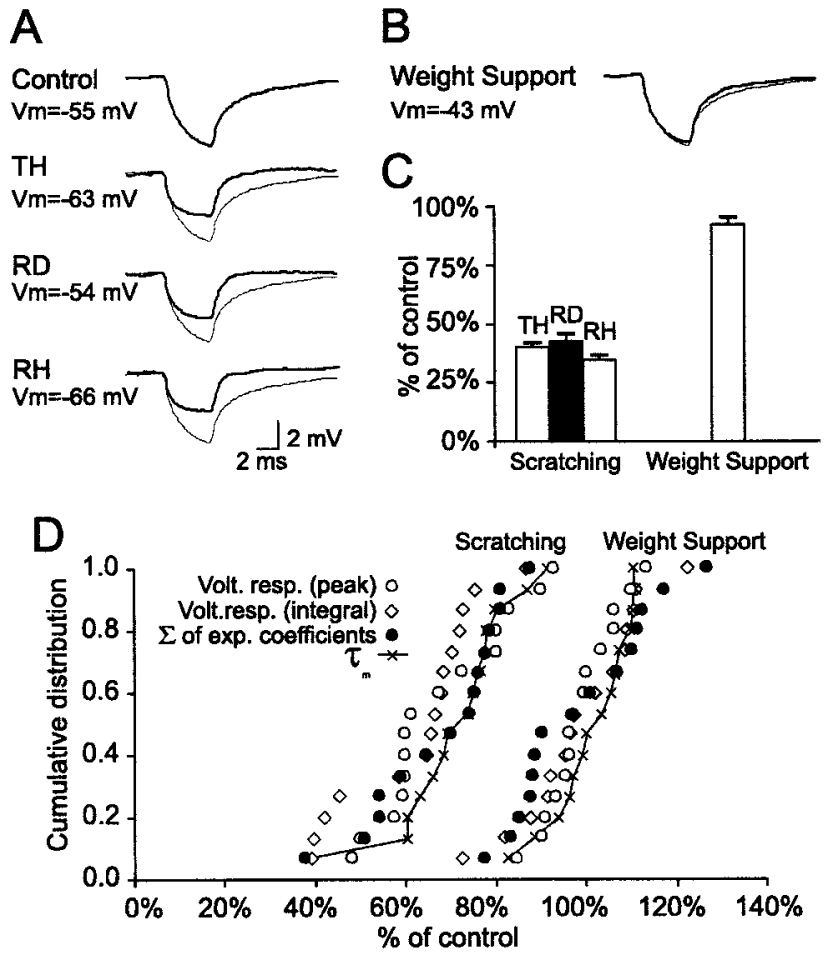

Figure 2. Differential change in input resistance during fictive scratching and weight support. $A, B$, Trace averages (18-54 sweeps) of the voltage deflections produced in an LGS2 motoneuron by short hyperpolarizing current pulses ( $-4 \mathrm{nA}, 5 \mathrm{msec}$ ) at rest (top control trace in $A$ ), during the three phases of scratching (bottom three traces in $A$ ), and during weight support $(B)$. To facilitate comparisons, the control trace was superimposed (thin trace). The time and voltage scales in $A$ are valid also in $B . C$, Normalized, average changes in input resistance as calculated with the integral method during the $\mathrm{TH}, \mathrm{RD}$, and $\mathrm{RH}$ phases of scratching and during weight support. $D$, Cumulative distributions of the changes in input resistance and membrane time constant during both fictive scratching (average across all phases) and weight support (both of the measurements with negative and positive current pulses are included). The values for each method used to estimate the changes in input resistance and for $\tau_{\mathrm{m}}$ were plotted in increasing order. The correlations between the different measurements were strong during both fictive scratching $(r=$ 0.88 integral vs peak; $r=0.96$ integral vs $\Sigma$ of exp coefficients; and $r=0.91$ integral vs $\left.\tau_{\mathrm{m}}\right)$ and weight support $(r=0.98$ integral vs peak; $r=0.97$ integral vs $\Sigma$ of exp coefficients; and $r=0.97$ integral vs $\tau_{\mathrm{m})}$.

during fictive scratching. The effects on $\mathrm{R}_{\mathrm{in}}$ and driving potentials are presented separately.

\section{Effect on $R_{\text {in }}$}

Voltage-sensitive conductances might have been activated during fictive scratching and weight support. However, the important question is whether they could explain the large changes in $\mathrm{R}_{\mathrm{in}}$ that were observed in this study. Thus, in four of the 13 motoneurons, the effects of continuous current injections on $\mathrm{R}_{\text {in }}$ were examined in the absence of motor activity, with currents of negative and/or positive polarity. The current injections were given in addition to the transient test pulses for $\mathrm{R}_{\text {in }}$ monitoring and were first delivered at rest before the induction of fictive motor activity (Fig. 4, curved arrows). Different current amounts were used in each motoneuron, and, in all cases, the amplitude of the membrane voltage displacement induced was either as large as or larger than those encountered during scratching and weight support activities (see Results, Driving potentials during fictive scratching and weight support).
Negative current injections at rest had only a small effect on $\mathrm{R}_{\mathrm{in}}$ (average decrease of $9.3 \pm 1.5 \% ; p=0.012$ ). This suggests that an activation of hyperpolarization-sensitive conductances (Barrett et al., 1980) would contribute very little to the large decreases in $\mathrm{R}_{\text {in }}$ observed during the $\mathrm{TH}$ and $\mathrm{RH}$ phases of scratching (average decrease, $\sim 40 \%$ in both cases). In comparison, positive current injections could substantially decrease the $\mathrm{R}_{\text {in }}$ of extensor motoneurons (Brownstone et al., 1994). Such substantial decreases $(\geq 25 \%)$ were presumed to be attributable to the activation of depolarization-sensitive conductances and were seen only when the current injected was large enough to displace the membrane potential to a value more positive than $-50 \mathrm{mV}$. In Figure $4 A$, for instance, a $32 \mathrm{nA}$ current injection depolarized the membrane to $-42 \mathrm{mV}$ and decreased $\mathrm{R}_{\text {in }}$ by $46 \%$. There were some motoneurons recorded during fictive scratching that had membrane potential excursions over $-50 \mathrm{mV}$ during the RD phase (P12, P13, P14, LGS1, and LGS4). Four of those motoneurons displayed such membrane potential excursions during fictive weight support as well. In the latter condition, however, large changes in $\mathrm{R}_{\text {in }}$ were not observed. Therefore, as for the $\mathrm{TH}$ and $\mathrm{RH}$ phases of scratching, it is unlikely that the decrease in $\mathrm{R}_{\text {in }}$ during the RD phase was attributable primarily to the activation of voltage-sensitive conductances. This conclusion is valid for the membrane region electrotonically close to the recording site, which is believed to constitute a large fraction of the total membrane area (Fleshman et al., 1988; Clements and Redman, 1989).

\section{Effects on driving potentials}

The effects of continuous current injections on the driving potentials were examined in five of the 13 motoneurons and one additional MG motoneuron (see below). Currents of negative and/or positive polarity were used. The most obvious effect of negative current injections during scratching was a reversal of the initial TH potential (Fig. 4, compare $A, B$ ). Reversal of TH was observed in all of the motoneurons and occurred when the membrane potential was shifted to values more negative than $-70 \mathrm{mV}$, i.e., more negative potential than the reversal potential for inhibitory synaptic conductances in cat motoneurons (Coombs et al., 1955). Interestingly, the small hyperpolarizing potentials seen just before the onset of $\mathrm{TH}$ in Figure 4 were also reversed when the membrane potential was shifted from -42 and $-91 \mathrm{mV}$ (compare the intracellular trace in $A a$ and $B b)$.

In contrast to the $\mathrm{TH}$ potential, negative current injections never reversed the RH potentials. Disfacilitation (removal of excitation) cannot explain this observation because $\mathrm{RH}$ potentials are associated with a decrease rather than an increase in $R_{\text {in }}$ (see Results, Phasic modulation of $\mathrm{R}_{\text {in }}$ during fictive scratching). Two other nonexclusive possibilities are that (1) the conductances mediating $\mathrm{RH}$ are located farther away from the soma (recording site) than those mediating $\mathrm{TH}$ and (2) the two potentials involve a different type of ion (e.g., potassium vs chloride conductances). To examine these possibilities, one additional experiment was performed in which an MG motoneuron was recorded using a chloride-containing electrode. The experiment is illustrated in Figure 5 and shows that both potentials can be successfully reversed with chloride ions in the electrode. The fact that the $\mathrm{TH}$ potential already reversed as the ions passively diffused into the cell (Fig. $5 A$, no current) whereas the RH potentials clearly reversed only when the chloride concentration was increased actively by current injection (Fig. $5 C$ ) would support the hypothesis of a more remote location for the conductances mediating the 
A

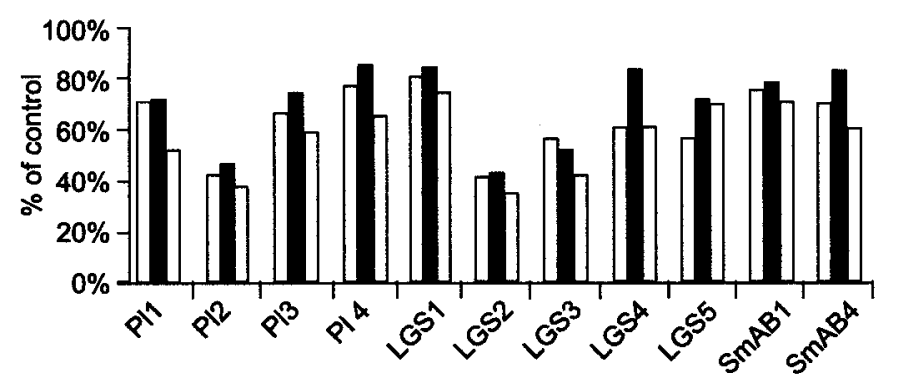

B

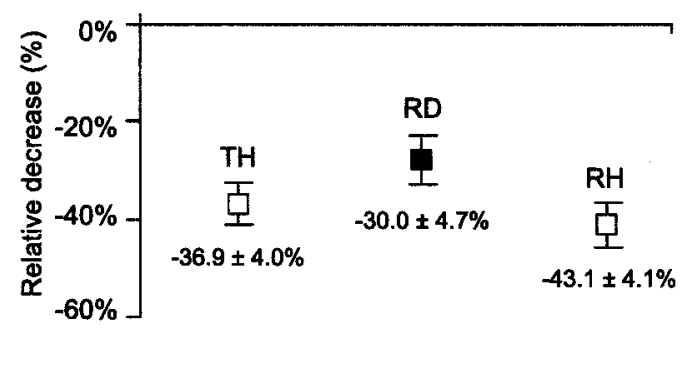

Figure 3. Weak phasic modulation of input resistance during fictive scratching. A, Average changes in input resistance for each of the 11 extensor motoneurons recorded during fictive scratching. As in Figure $2 C$, the average resistance during the RD phase of scratching (solid bar) is flanked on the left by the average during the $\mathrm{TH}$ phase and, on the right, by the average during the $\mathrm{RH}$ phase. The integral method was used, and the measurements with negative and positive current pulses were pooled together. $B$, Mean decrease in input resistance during the different phases of scratching. The means are displayed with the SEs.
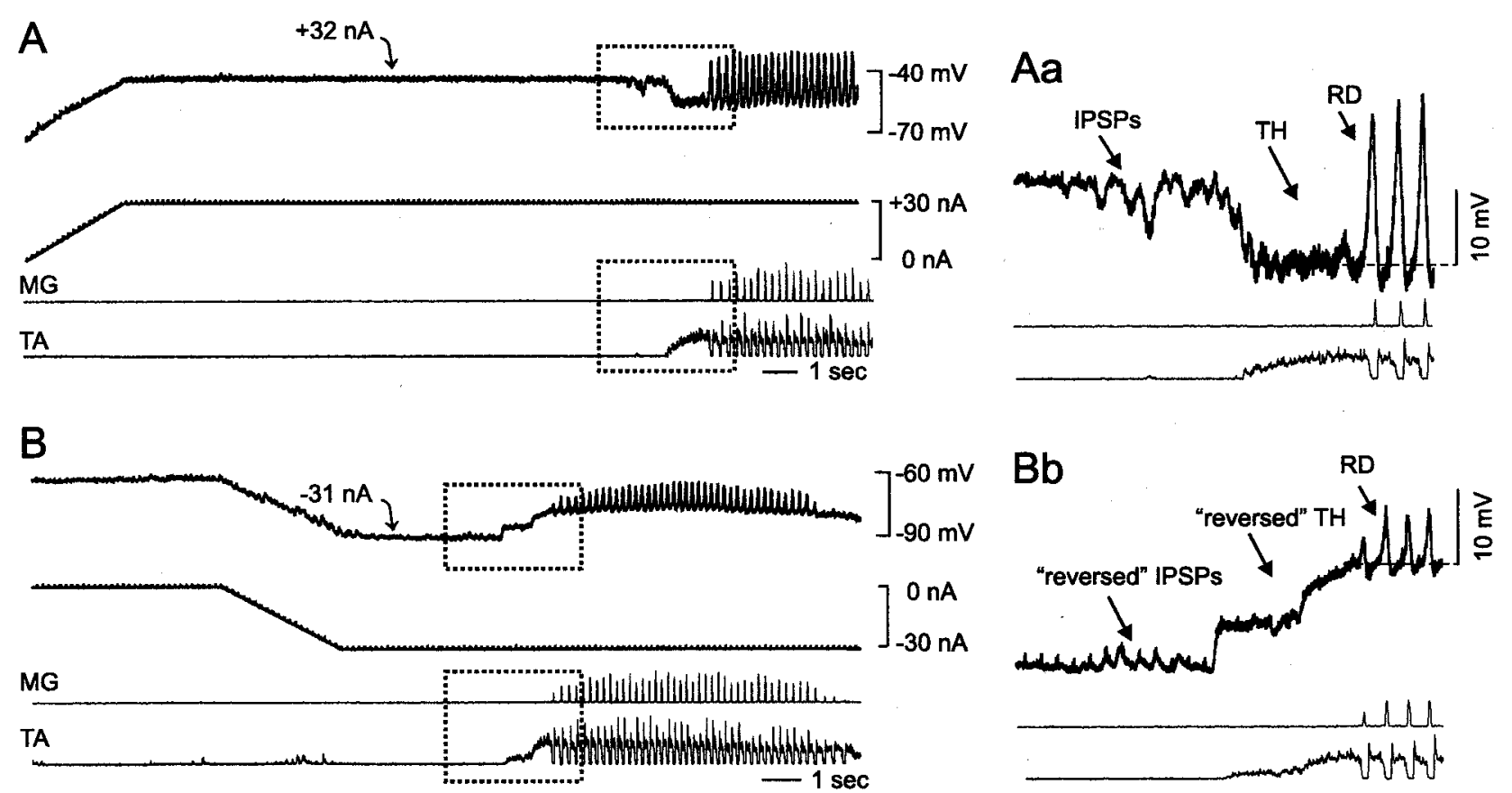

Figure 4. Effects of continuous current injections on the driving potentials during scratching. Continuous depolarizing $(A)$ and hyperpolarizing $(B)$ current injections in LGS4 motoneurons kept the membrane potential at -42 and $-91 \mathrm{mV}$, respectively. In the absence of bias current, the membrane potential was approximately $-63 \mathrm{mV}$. From top to bottom, the traces show the membrane potential (top trace), the current injection (second trace), and ENGs from the MG and TA muscle nerves (bottom two traces). In addition to the continuous current injections, short current pulses ( $+1.5 \mathrm{nA}, 5 \mathrm{msec})$ were given to measure the changes in input resistance (small vertical bars on top of the current injection trace). A few seconds after the membrane potential stabilized, fictive scratching was induced. $A a, B b$, The series of events that occurred around the induction time (portions of the traces enclosed in dotted rectangles) displayed on a larger scale. The fluctuations in the membrane potential trajectory during the transition between rest and motor activity (step-like, reversed hyperpolarization in $B$ ) was not uncommon. It is presumably attributable to the lack of fine control over the stimulus used to induce scratching (applied manually). Note that the fluctuation recorded intracellularly was also seen in the population response from the antagonist motoneuron pool (TA ENG).

RH potentials. As can be expected from potentials mediated by chloride conductances, when positive current was injected, both TH and RH potentials had slightly increased amplitudes (mean increase of $6.1 \pm 2.0 \mathrm{mV}$ for $\mathrm{TH}$ and $0.3 \pm 0.4 \mathrm{mV}$ for $\mathrm{RH})($ data not shown).

\section{DISCUSSION}

The main finding of this study was a distinct modulation of the membrane resistance of extensor motoneurons during fictive scratching and weight support. Fictive scratching could reduce the input resistance by $>50 \%$, with a majority of motoneurons show- ing an average decrease of $>25 \%$. Fictive weight support, which often involved voltage displacements of similar or larger amplitudes than those observed during fictive scratching, rarely produced such large average decreases in $\mathrm{R}_{\mathrm{in}}$. It is suggested that the differential effect on $R_{\text {in }}$ is primarily attributable to a difference in synaptic drive during the two motor activities and a larger amount of inhibitory synaptic conductance during fictive scratching.

The fact that average decrease in $\mathrm{R}_{\mathrm{in}}$ during fictive scratching is comparable with that reported by others during fictive locomotion would support the idea that the membrane resistance may be optimally changed during rhythmic activities (see introductory 


\section{A}

Figure 5. Chloride injection reverses the hyperpolarizing drive potentials during fictive scratching. Effect of chloride injections on the membrane potential trajectory of an $\mathrm{MG}$ motoneuron during fictive scratching. $A$, Chloride ions diffused passively from the electrode. $B, C$, Chloride ions were actively ejected using negative current. For other details, see Figure 1.

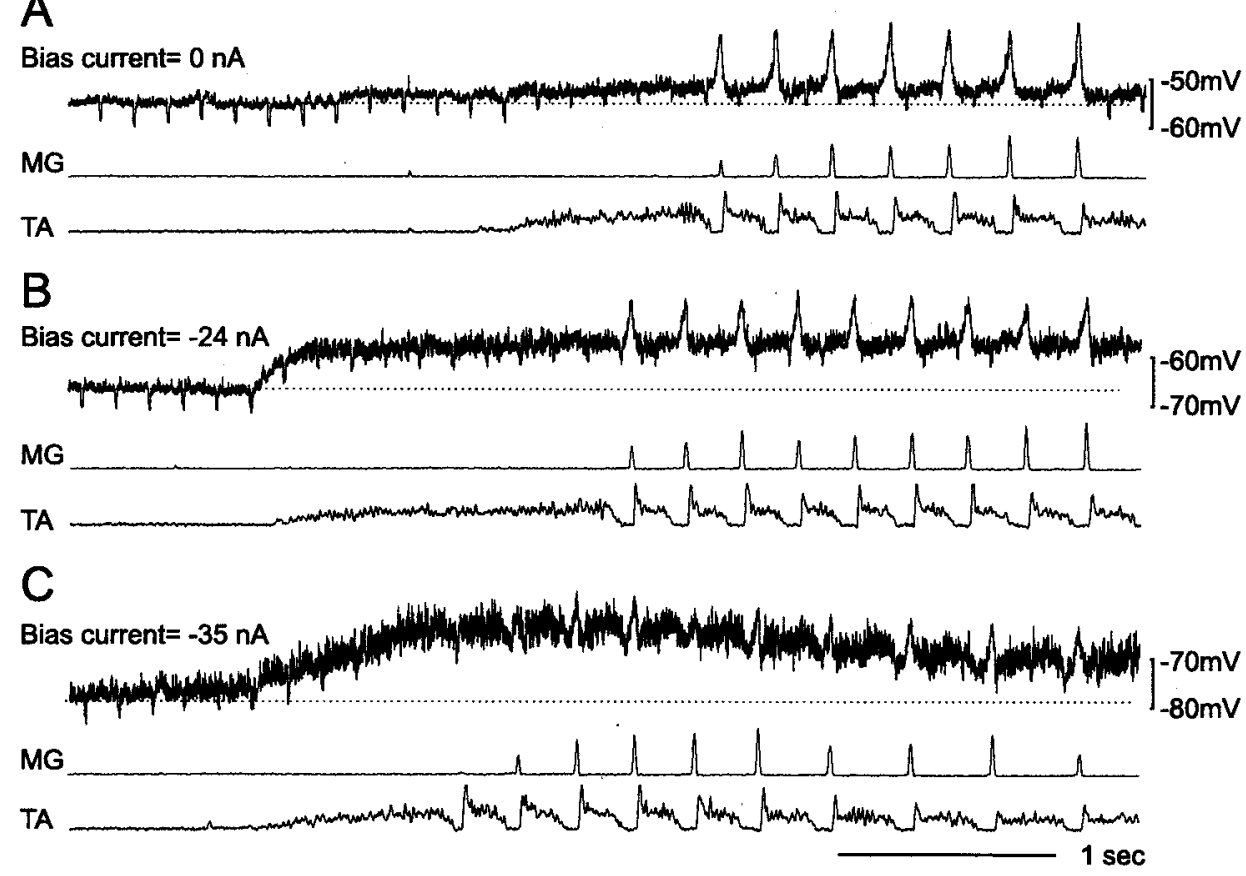

remarks). Clearly, however, the present study indicates that membrane resistance can also vary from one activity to another.

\section{Technical considerations}

Although $\mathrm{R}_{\mathrm{in}}$ is an indirect measure of membrane resistance and may not be sensitive to changes in conductance in cell compartments far away from the recording site, there is little doubt that the observed changes in $\mathrm{R}_{\text {in }}$ were caused by changes in membrane resistance. The fact that the exact location of the conductances responsible for the decreases in $\mathrm{R}_{\text {in }}$ is unknown does not change the present conclusions that the membrane resistance of individual motoneurons was affected differentially during fictive scratching and fictive weight support.

The absolute amplitude of the voltage transients in this study may have been influenced by both electrode penetration (Svirskis et al., 1997 and references therein) and the use of QX-314 in the electrode solution (Talbot and Sayer, 1996; Lee and Heckman, 1999). To speculate about the impact of this influence would require a comparison with the true, but yet unknown, $\mathrm{R}_{\mathrm{in}}$ value. However, because QX-314 and possibly an electrode shunt were present during all recording conditions, these factors are unlikely to affect the present conclusion of a larger increase in motoneuron conductance during fictive scratching than during weight support.

\section{Differences in synaptic drive during fictive scratching and weight support}

The synaptic nature of the hyperpolarizing potentials during scratching ( $\mathrm{TH}$ and $\mathrm{RH}$ ) was investigated, and the data suggest that both potentials are mediated by inhibitory synaptic inputs. In contrast, the amount of excitatory conductance that contribute to the depolarizing potentials during scratching (RD) and weight support remains unknown. In addition to excitatory synaptic inputs, disinhibition (removal of inhibitory synaptic inputs) could be a contributing factor. Disinhibition could in theory explain the smaller decrease in $\mathrm{R}_{\text {in }}$ during the $\mathrm{RD}$ phase of scratching and the occasional small increases in $\mathrm{R}_{\text {in }}$ during fictive weight support by increasing $\mathrm{R}_{\mathrm{in}}$ and opposing a decrease in $\mathrm{R}_{\text {in }}$ attributable to excitatory inputs. Finally, a simultaneous contribution from exci- tation and inhibition is also possible during the depolarizing potentials during both scratching (RD) and weight support. Concurrent excitatory and inhibitory synaptic inputs have been reported during various forms of fictive scratching (Robertson and Stein, 1988) and rhythmic motor activities (Perret, 1986; Raastad et al., 1997; Parkis et al., 1999). Whatever the contributing factors during the RD phase of scratching and during weight support, the differential effect on $\mathrm{R}_{\text {in }}$ during the two activities would be explained by a higher total synaptic activity during scratching. In light of the above considerations, it also appears that the main difference in synaptic drive between fictive scratching and weight support is a stronger inhibitory drive during fictive scratching.

\section{Possible sources of synaptic conductances}

Lumbar motoneurons in the cat may bear as much as 50,000140,000 synaptic boutons (Örnung et al., 1998), and it is generally believed that most of this synaptic contingent arises from lastorder spinal interneurons (Rekling et al., 2000). Unfortunately, information about last-order spinal interneurons is scarce in the cat, which limits the number of conjectures about the source of synaptic inputs during fictive scratching and weight support.

The depolarizing potentials during fictive scratching (RD) and weight support are assumed to be mediated by excitatory (presumably glutamatergic) spinal interneurons. Few candidates exist (Cavallari et al., 1987; Jankowska, 1992; McCrea, 1998). These have not been recorded during fictive scratching and weight support, but some display rhythmic discharge during fictive locomotion (Shefchyk et al., 1990; McCrea, 1998).

According to the present study, the hyperpolarizing potentials during fictive scratching ( $\mathrm{TH}$ and $\mathrm{RH}$ ) are mediated by inhibitory synaptic events involving chloride conductances, although an additional contribution from potassium conductances during the $\mathrm{RH}$ phase cannot be excluded. Consequently, both potentials could be mediated by neurons containing glycine and/or GABA. For the time being, there exists more argument in favor of glycine as a candidate. First, the number of presynaptic boutons and postsynaptic receptors in $\alpha$-motoneurons is larger for glycine than 
GABA (Alvarez et al., 1996, 1997; Örnung et al., 1998). Second, glycine is known to play an important role in shaping motoneuron activity during scratching in nonmammalian vertebrates (Currie and Lee, 1997). Very few last-order glycine-containing interneurons have been characterized (Jankowska, 1992), but both the Ia inhibitory and the Renshaw interneurons may be capable of inhibiting motoneurons during fictive scratching (Deliagina and Orlovsky 1980; Deliagina and Feldman 1981; Degtyarenko et al., 1998). Based on their finding that Renshaw IPSPs were less sensitive to changes in intracellular chloride concentration than the Ia IPSPs, Burke et al. (1971) have put forward the interesting suggestion that the Renshaw synapses are located farther away from soma than the synapses from the Ia inhibitory interneurons (for supportive anatomical evidence, see Fyffe, 1991). From this and the present finding that the RH phase of scratching was more difficult to reverse than the initial TH phase emerge the possibility that Renshaw and Ia interneurons contribute to the $\mathrm{RH}$ and $\mathrm{TH}$ potential, respectively.

\section{Impact on synaptic integration}

One possible consequence of the present finding is that the integrative properties of the motoneurons are different during fictive scratching and weight support but similar during weight support and rest. In this context, it is an interesting theoretical prediction by Korogod et al. (2000) that, in conditions of low background synaptic activity, the dendrites of motoneurons are more efficient in transferring synaptic currents to soma.

Because $\tau_{\mathrm{m}}$ was reduced during fictive scratching, synaptic integration would be affected also in the temporal domain. A shorter integration time would conveniently limit the duration of inhibitory synaptic actions and be particularly useful during fast, rhythmic activity, such as scratching.

\section{REFERENCES}

Alvarez FJ, Taylor-Blake B, Fyffe RE, De Blas AL, Light AR (1996) Distribution of immunoreactivity for the beta 2 and beta 3 subunits of the GABAA receptor in the mammalian spinal cord. J Comp Neurol 365:392-412.

Alvarez FJ, Dewey DE, Harrington DA, Fyffe RE (1997) Cell-type specific organization of glycine receptor clusters in the mammalian spinal cord. J Comp Neurol 379:159-170.

Barrett EF, Barrett JN (1976) Separation of two voltage-sensitive potassium currents, and demonstration of a tetrodotoxin-resistant calcium current in frog motoneurones. J Physiol (Lond) 255:737-774.

Barrett EF, Barrett JN, Crill WE (1980) Voltage-sensitive outward currents in cat motoneurones. J Physiol (Lond) 304:251-276.

Berkinblit MB, Deliagina TG, Orlovsky GN, Feldman AG (1980) Activity of motoneurons during fictitious scratch reflex in the cat. Brain Res 193:427-438.

Brownstone RM, Gossard J-P, Hultborn H (1994) Voltage-dependent excitation of motoneurones from spinal locomotor centres in the cat. Exp Brain Res 102:34-44.

Burke RE, ten Bruggencate G (1971) Electrotonic characteristics of alpha motoneurones of varying size. J Physiol (Lond) 212:120.

Burke RE, Fedina L, Lundberg A (1971) Spatial synaptic distribution of recurrent and group Ia inhibitory systems in cat spinal motoneurones. J Physiol (Lond) 214:305-326.

Cavallari P, Edgley SA, Jankowska E (1987) Post-synaptic actions of midlumbar interneurones on motoneurones of hind-limb muscles in the cat. J Physiol (Lond) 389:675-689.

Cazalets JR, Borde M, Clarac F (1996) The synaptic drive from the spinal locomotor network to motoneurons in the newborn rat. J Neurosci 16:298-306.

Clements JD, Redman SJ (1989) Cable properties of cat spinal motoneurones measured by combining voltage clamp, current clamp and intracellular staining. J Physiol (Lond) 409:63-87.

Coombs JS, Eccles JC, Fatt P (1955) The specific ionic conductances and the ionic movements across the motoneuronal membrane that produce the inhibitory post-synaptic potential. J Physiol (Lond) 130:326-373.

Currie SN, Lee S (1997) Glycinergic inhibition contributes to the generation of rostral scratch motor patterns in the turtle spinal cord. J Neurosci 17:3322-3333.
Degtyarenko AM, Simon ES, Norden-Krichmar T, Burke RE (1998) Modulation of oligosynaptic cutaneous and muscle afferent reflex pathways during fictive locomotion and scratching in the cat. J Neurophysiol 79:447-463.

Deliagina TG, Feldman AG (1981) Activity of Renshaw cells during fictive scratch reflex in the cat. Exp Brain Res 42:108-115.

Deliagina TG, Orlovsky GN (1980) Activity of Ia inhibitory interneurons during fictitious scratch reflex in the cat. Brain Res 193: 439-447.

Domer FR, Feldberg W (1960) Scratching movements and facilitation of the scratch reflex produced by tubocurarine in cats. J Physiol (Lond) 153:35-51.

Feldberg W, Fleischhauer K (1960) Scratching movements evoked by drugs applied to the upper cervical cord. J Physiol (Lond) 151:502-517.

Fleshman JW, Segev I, Burke RB (1988) Electrotonic architecture of type-identified alpha-motoneurons in the cat spinal cord. J Neurophysiol 60:60-85.

Fyffe R (1991) Spatial distribution of recurrent inhibitory synapses on spinal motoneurons in the cat. J Neurophysiol 65:1134-1149.

Gelfand IM, Orlovsky GN, Shik ML (1988) Locomotion and scratching in tetrapods. In: Neural control of rhythmic movements in vertebrate (Cohen AH, Rossignol S, Grillner S, eds), pp 167-199. New York: Wiley.

Gosgnach S, Quevedo J, Fedirchuk B, McCrea DA (2000) Depression of group Ia monosynaptic EPSPs in cat hindlimb motoneurones during fictive locomotion. J Physiol (Lond) 526:639-652.

Gustafsson B, Pinter MJ (1984) Relations among passive electrical properties of lumbar alpha-motoneurones of the cat. J Physiol (Lond) 356:401-431.

Hochman S, McCrea DA (1994) Effects of chronic spinalization on ankle extensor motoneurons. II. Motoneuron electrical properties. J Neurophysiol 71:1468-1479.

Ito M, Oshima T (1965) Electrical behaviour of the motoneurone membrane during intracellularly applied current steps. J Physiol (Lond) 180:607-635.

Jankowska E (1992) Interneuronal relay in spinal pathways from proprioceptors. Prog Neurobiol 38:335-378.

Korogod SM, Kulagina IB, Horcholle-Bossavit G, Gogan P, Tyc-Dumont S (2000) Activity-dependent reconfiguration of the effective dendritic field of motoneurons. J Comp Neurol 422:18-34.

Lee RH, Heckman CJ (1999) Paradoxical effect of QX-314 on persistent inward currents and bistable behavior in spinal motoneurons in vivo. J Neurophysiol 82:2518-2527.

McCrea DA (1998) Neuronal basis of afferent-evoked enhancement of locomotor activity. Ann NY Acad Sci 860:216-225.

Örnung G, Ottersen OP, Cullheim S, Ulfhake B (1998) Distribution of glutamate-, glycine- and GABA-immunoreactive nerve terminals on dendrites in the cat spinal motor nucleus. Exp Brain Res 118:517-532.

Parkis MA, Dong X, Feldman JL, Funk GD (1999) Concurrent inhibition and excitation of phrenic motoneurons during inspiration: phasespecific control of excitability. J Neurosci 19:2368-2380.

Perreault M-C (1999) Reduction of the input resistance of extensor motoneurones during fictive scratching. Soc Neurosci Abstr 25:562.5.

Perreault M-C, Enriquez-Denton M, Hultborn H (1999) Proprioceptive control of extensor activity during fictive scratching and weight support compared to fictive locomotion. J Neurosci 19:10966-10976.

Perret C (1986) Synaptic influences contributing to the pattern of limb motoneuron activity during fictive locomotion in the cat. In: Neurobiology of vertebrate locomotion (Grillner S, Stein PSG, Stuart DG, Forssberg H, Herman RH, eds), pp 173-184. New York: Macmillan.

Raastad M, Johnson BR, Kiehn O (1997) Analysis of EPSCs and IPSCs carrying rhythmic, locomotor-related information in the isolated spinal cord of the neonatal rat. J Neurophysiol 78:1851-1859.

Raastad M, Enriquez-Denton M, Kiehn O (1998) Synaptic signaling in an active central network only moderately changes passive membrane properties. Proc Natl Acad Sci USA 95:10251-10256.

Rekling JC, Funk GD, Bayliss DA, Dong XW, Feldman JL (2000) Synaptic control of motoneuronal excitability. Physiol Rev 80:767-852.

Robertson GA, Stein PS (1988) Synaptic control of hindlimb motoneurones during three forms of the fictive scratch reflex in the turtle. J Physiol (Lond) 404:101-128.

Shefchyk SJ, Jordan LM (1985) Motoneuron input-resistance changes during fictive locomotion produced by stimulation of the mesencephalic locomotor region. J Neurophysiol 54:1101-1108.

Shefchyk S, McCrea D, Kriellaars D, Fortier P, Jordan L (1990) Activity of interneurons within the L4 spinal segment of the cat during brainstem-evoked fictive locomotion. Exp Brain Res 80:290-295.

Svirskis G, Gutman A, Hounsgaard J (1997) Detection of a membrane shunt by DC field polarization during intracellular and whole cell recording. J Neurophysiol 77:579-586.

Talbot MJ, Sayer RJ (1996) Intracellular QX-314 inhibits calcium currents in hippocampal CA1 pyramidal neurons. J Neurophysiol 76:2120-2124.

Zengel JE, Reid SA, Sypert GW, Munson JB (1985) Membrane electrical properties and prediction of motor-unit type of medial gastrocnemius motoneurons in the cat. J Neurophysiol 53:1323-1344. 